\title{
Electrochemical parameters and biocompatibility of bare Nitinol surfaces
}

\author{
${ }^{\text {a }}$ S. Shabalovskaya ${ }^{1,2}$, G. Rondelli ${ }^{3}$ and M. Rettenmayr ${ }^{1}$ \\ ${ }^{1}$ Institute of Materials Science and Technology, Metallic Materials, Friedrich-Schiller University, Loebdergraben \\ 32, 07743 Jena, Germany \\ ${ }^{2}$ Ames Laboratory-DOE, Iowa State University, Ames, IA, 50011, USA \\ ${ }^{3}$ Institute of Energy and Interphases, CNR, Milano, Italy
}

\begin{abstract}
For understanding the nature of the variable thrombogenicity of bare Nitinol surfaces, a systematic study of electrochemical parameters was performed on disc and wire samples using cyclic potential polarization, open circuit potential and polarization resistance. The surfaces treated using chemical solutions showed consistent corrosion behavior, but mechanically polished and heat treated samples were prone to pitting. The polarization resistance of bare Nitinol surfaces varied in a range from $100 \mathrm{~K} \Omega \mathrm{cm}^{2}$ to $10 \mathrm{M} \Omega \mathrm{cm}^{2}$, and the open circuit potentials from $-440 \mathrm{mV}$ to $-55 \mathrm{mV}$ implying the variability in corrosion rate and surface reactivity. Ni surface concentrations and ion release are discussed in terms of surface charge in connection with fibrinogen adsorption and platelet activation.
\end{abstract}

\section{Introduction}

Nitinol, a group of nearly equiatomic shape memory and superelastic alloys, is an established biomaterial, whose biocompatibility is heavily grounded on the inertness of $\mathrm{Ti}$ based oxides that usually dominate the surface exterior [1,2]. At present, there are a number of bare Nitinol surfaces that may be considered for implantation. These are mechanically polished, electropolished, chemically etched, passivated boiling in water or using heat treatments and anodized [3]. It is not clear, however, what common parameter can be used to compare these surfaces that are varying significantly in their chemistry, topography and corrosion resistance. The present study is not focusing merely on corrosion. The electrochemical surface parameters were explored systematically in order to reveal regularities in the behavior of native Nitinol surfaces for a better understanding of biological response. The surfaces resulting from our previous studies were evaluated using cyclic potential polarization, open circuit potential (OCP) and polarization resistance (Rp), and the obtained results are implemented in the discussion of the biological aspects involved.

\section{Materials and methods}

Disk samples of $16 \mathrm{~mm}$ diameter were cut from a rod of $\mathrm{Ni}_{50.8} \mathrm{Ti}_{49.2}$ alloy (Memry Corporation, USA) using electro-discharge machining, and the damaged surface layers were eliminated using chemical etching. Samples were then mechanically polished (Mp) with $\mathrm{SiC}$ paper to $1 \mu \mathrm{m}$ finish. This was the original surface state. Further discs were either chemically etched (Ce) again in $1 \mathrm{HF}+4 \mathrm{HNO}_{3}$ aqueous solution or electropolished (Ep) and then also boiled in distilled water (hereafter called as $\mathrm{CeWb}$, and $\mathrm{EpWb}$, respectively), or treated in hydrogen peroxide. A heat treatment $(\mathrm{Ht})$, mimicking shape setting, was performed in air at $520^{\circ} \mathrm{C}$ for $20 \mathrm{~min}$ for $\mathrm{Mp}, \mathrm{Ce}$ and $\mathrm{CeWb}$ samples, which are further referred to as $\mathrm{MpHt}, \mathrm{CeHt}$ and $\mathrm{CeWbHt}$, respectively. For comparison, certain measurements were also performed on superelastic wires of a $0.75 \mathrm{~mm}$ diameter (EUROFLEX GmbH and Fort Wayne Metals, IN, USA) treated in a manner similar to the disks.

The electrochemical studies were carried out in a $0.9 \mathrm{NaCl}$ solution at room temperature using a PAR 273A potentiostat and a three electrode configuration (working electrode, counter graphite and reference $\mathrm{Ag} / \mathrm{AgCl}$ electrodes). In the present paper, all the potentials are presented relative to the saturated calomel electrode (SCE). The solution was continuously purged with nitrogen during the measurements.

${ }^{a}$ e-mail : svetinoleyahoo.com

This is an Open Access article distributed under the terms of the Creative Commons Attribution-Noncommercial License (http://creativecommons.org/licenses/by-nc/3.0/), which permits unrestricted use, distribution, and reproduction in any noncommercial medium, provided the original work is properly cited. 
The open circuit potential (OCP) and polarization resistance $(\mathrm{Rp})$ were measured before cyclic potential polarization tests. The OCP data were monitored for one hour and the final value was accepted. The Rp values $\left(\mathrm{M} \Omega \mathrm{cm}^{2}\right)$ were deduced from the slope of the curve of potential versus current density, recorded in the range of potentials from $20 \mathrm{mV}$ below to $20 \mathrm{mV}$ above OCP that was preliminarily defined. Each data point for OCP and $\mathrm{Rp}$ presents an average of the measurements of at least three samples. The potentiodynamic (PD) potential polarization was carried out at a sweeping rate of $0.167 \mathrm{mV} / \mathrm{min}$ beginning from $-600 \mathrm{mV}$ to potentials above $+1.000 \mathrm{mV}$. Scanning reversed automatically when the current density reached $100 \mu \mathrm{A} / \mathrm{cm}^{2}$.

\section{Results}

\subsection{Cyclic potential polarization}

The surfaces prepared on disc samples showed consistent corrosion behavior, with the exception of the Mp and $\mathrm{MpHt}$ surfaces. Representative curves for potentiodynamic cyclic potential polarization of Mp (1), Ce (2), Ep (3) and $\mathrm{CeWbHt}$ (4) samples are shown in Fig. 1. There was no surface breakdown up to the highest potentials $(\geq 1$ $\mathrm{V}$ ) and a minimal hysteresis, if any, on the reverse scans. The increase in currents at higher potentials is not due to corrosion, but possibly because of the oxygen evolution reaction. The reverse scans proceeded at current densities lower than those during direct scans, as demonstrated on the example of Ht samples in Fig. 1. There was a slight difference among the samples in the corrosion potentials that ranged from $-450 \mathrm{mV}$ to $-300 \mathrm{mV}$. A more distinct feature was the variation of the current density in the region of passive behavior, in the plateau of the current density. Thus in case of Ce samples, a perfect plateau was observed up to about $1.2 \mathrm{~V}$ (curve 2). For the Mp state, however, the current density showed a tendency to be slightly higher (curve 1), indicating a slightly higher material dissolution. After electropolishing, the current density was significantly reduced, but the passivity plateau became inclined (curve 3). It should be mentioned that from four Mp disks tested, three showed pitting at an average pitting potential of $+430 \mathrm{mV}$ due to crevices at the areas adjacent to the PTEE sample holders.

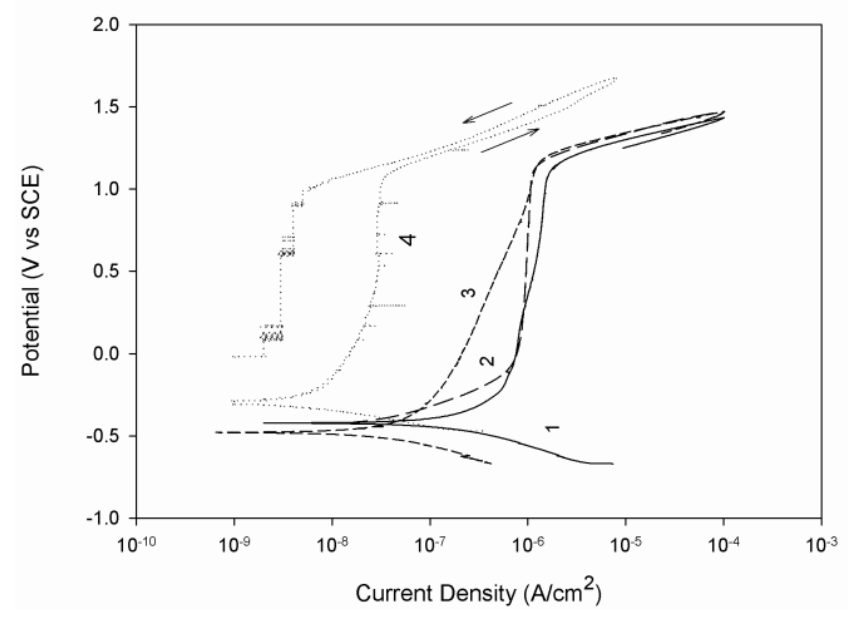

Fig. 1. Potentiodynamic cyclic potential polarization for Nitinol disc samples in mechanically polished (1), chemically etched (2), electropolished (3), chemically etched, boiled in water and heat treated (4) samples. A reverse scan is also presented for sample 4 .

The Ht samples exhibited almost two orders of magnitudes lower current density and current spikes that were interpreted as a tendency to form metastable pits. The performance of the MpHt samples was inferior to CeWbHt samples due to pitting at approx. 600-700 $\mathrm{mV}$ and crevices. 


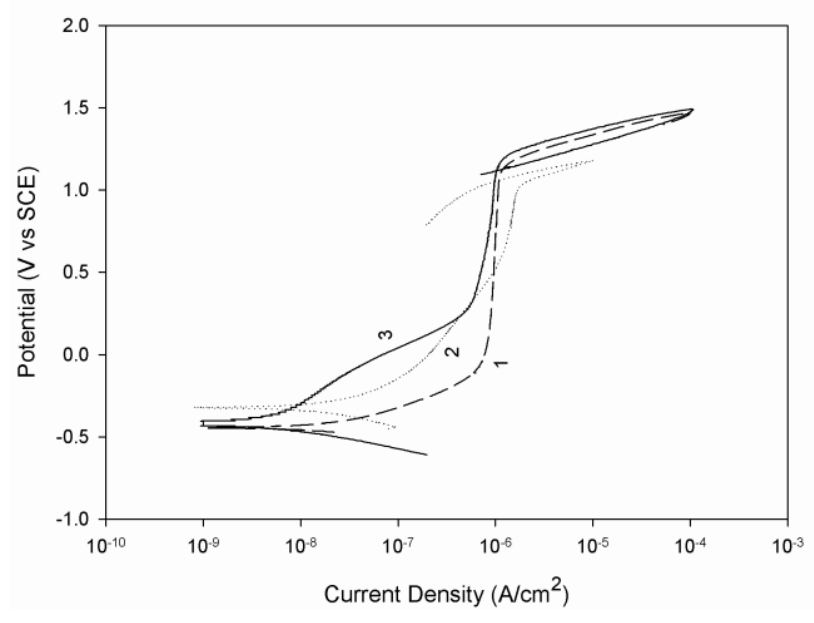

Fig. 2. Potentiodynamic cyclic polarization for chemically etched (1), chemically etched and boiled in water (3) and hydrogen peroxide treated disc samples (2).

Importantly, in the present study for the first time we revealed certain subtle differences in the corrosion behavior between $\mathrm{Ce}$ (or Ep) and additionally $\mathrm{Wb}$ samples. Boiling in water caused a slight $(\sim 100 \mathrm{mV})$ extension of the passivity region and significantly reduced currents at potentials above the corrosion potential, pointing to a drop in the anodic dissolution of the material. The PD curve for a Nitinol sample treated in hydrogen peroxide is situated between the curves for $\mathrm{Ce}$ and CeWb samples (Fig. 2, curve 2). Obviously, boiling in water reduced the current density more effectively than hydrogen peroxide treatment. A similar effect, although less pronounced, was also observed after boiling in water of the electropolished samples (not shown). An evaluation of the corrosion currents from the cyclic potential polarization curves presented above showed that they did not exceed $10 \mathrm{nA}$. After the corrosion studies, the surfaces were examined using SEM. No traces of localized corrosion were identified on the surfaces of the samples, whose polarization scans are shown in Fig. 1 and 2, but single pits that could also be seen with unarmed eyes were observed on the surfaces of $\mathrm{Mp}$ and $\mathrm{Ht}$ samples (Fig. 3).
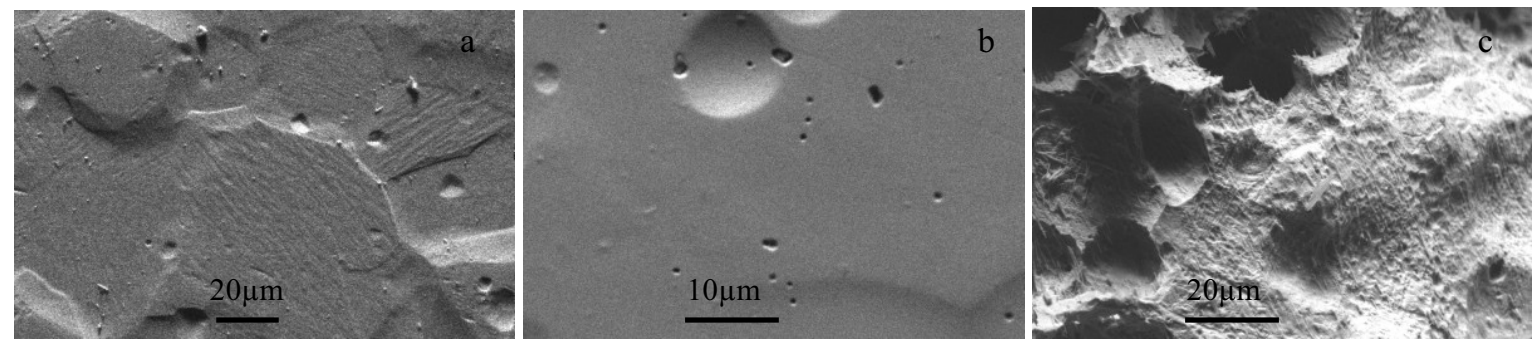

Fig. 3. Representative SEM images of the surfaces of Nitinol samples after the corrosion experiments. No traces of localized corrosion can be seen in the case of the samples chemically etched and boiled in water (a), or treated in hydrogen peroxide (b). Localized corrosion and pits on the surfaces of heat treated samples are exemplified (c).

\subsection{Open circuit potentials and polarization resistance}

The results of the evaluation of polarization resistance and open circuit potential for Nitinol surfaces of disk samples are presented in Fig. 4. For comparison, the data for certain Nitinol wire samples and data from the literature [4] are also included. It can be seen that the OCP for Nitinol surfaces varied in a wide range from as low as $-440 \mathrm{mV}$ for the Ep to as high as $-55 \mathrm{mV}$ for the CeHt samples. The Rp also varied dramatically, from as low as $10^{5} \Omega \mathrm{cm}^{2}$ for the Mp to $10^{7} \Omega \mathrm{cm}^{2}$ for the EpWb samples. 


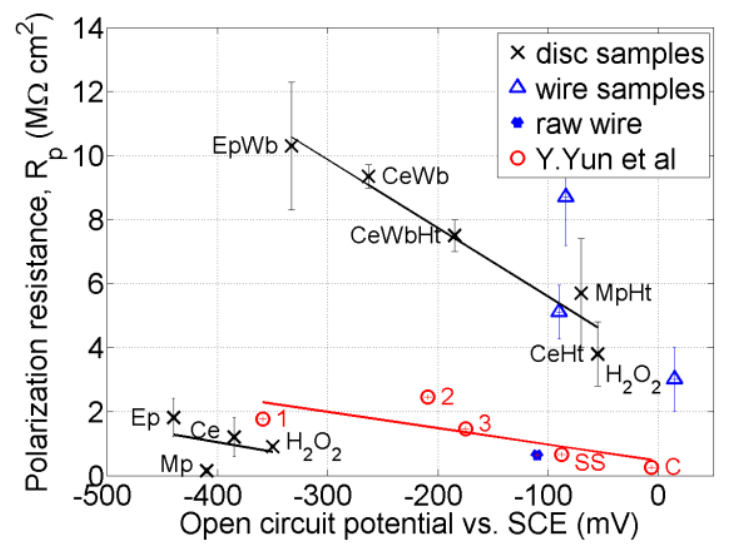

Fig. 4. Polarization resistance (Rp) and open circuit potential (OCP) for various Nitinol surfaces of disc (x) and wire samples $(\Delta)$. The sample designation is described in section 2 . The standard deviations for the OCP varied from \pm 10 to $\pm 30 \mathrm{mV}$, and only for Ce samples it was $\pm 60 \mathrm{mV}$. For comparison, the results of the studies of other materials from Ref. 4 are also presented. (o) - Zr2.5Nb (1), Ti13Nb13Zr (2), Ti6Al4V (3), stainless steel (SS) and carbon (C).

Obviously, there are two groups of surfaces. The first group includes $\mathrm{Mp}$, Ep and Ce surfaces with Rp values lower than $2 \mathrm{M} \Omega \mathrm{cm}^{2}$ and with OCP that are the most active (negative) observed. The second group embraces those samples that showed OCP values nobler than $-330 \mathrm{mV}$ and higher Rp values from 4 to $10 \mathrm{M} \Omega$ $\mathrm{cm}^{2}$. It can also be seen that there is a linear dependence between Rp and OCP, at least for the samples from the second group. The results obtained for the treated wire samples also could be fitted by the same curve. One data point, however, for a wire with an original black oxide does not belong to either of the two groups defined above. This wire with a thick black oxide studied earlier [5] has a nobler OCP, but a relatively low Rp pointing at a higher corrosion rate associated with oxide defectiveness. Another important observation is that the surfaces of disc and wire samples treated in hydrogen peroxide showed a great difference in the OCP. It is interesting that the OCP versus Rp dependence for other materials [4] such as $\mathrm{Zr}-\mathrm{Nb}$, Ti alloys, stainless steels and carbon steels plotted in Fig. 4 also exhibits a linear behavior. These latter surfaces showed Rp values in the range defined for the first group of Nitinol samples with less passive surfaces.

\section{Discussion}

Based on the present study it can be concluded that Nitinol corrosion behavior is quite predictable as opposed to the conclusion reached in Ref. 6 . Most of the prepared surfaces are highly resistant also to localized corrosion, a major concern in medical applications. The polarization resistance, inversely proportional to the corrosion rate, reflects the degree of protection of the passive surface layers. The great variation in Rp values among the studied Nitinol surfaces from $10^{5} \Omega \mathrm{cm}^{2}$ to $10^{7} \Omega \mathrm{cm}^{2}$ (Fig. 4) points at a corresponding variability in the corrosion rates. This is in agreement with the estimates of the corrosion rates available from the literature (from 0.1 to $275 \mu \mathrm{m}$ per year $[7,8]$ ). The very high Rp values of up to $10^{7} \Omega \times \mathrm{cm}^{2}$ exceed significantly those reported for commercial titanium and Ti based medical alloys, which are in the interval of $10^{5}-10^{6} \Omega \mathrm{cm}^{2}$ (Fig. 4 and Ref. 9), implying a higher resistance of the prepared Nitinol surfaces to general corrosion. The highest corrosion rates among Nitinol surfaces should be expected from Mp surfaces and the lowest from EpWb, CeWb and CeWbHt. This correlates well with the fact that the Ni release (Table 1) is maximal in the first group of the surfaces (Mp, Ce, Ep) identified in the present study and minimal in the case of the surfaces that were additionally boiled in water $(\mathrm{CeWb})$ or heat treated $(\mathrm{CeWbHt})$.

The release of a certain amount of Ni from Nitinol surfaces is inevitable in corrosive solutions. From the comparison of the results for $\mathrm{Ni}$ release presented in Table 1 with $\mathrm{Ni}$ content in drinking water $(20 \mathrm{ng} / \mathrm{ml}$ [10]), or in the medium for cell growth (61 ng/ml [11]), it may be concluded that the Ni release we are dealing with is in a subtoxic range of $\mathrm{Ni}$ concentrations. Nevertheless, this non-significant $\mathrm{Ni}$ release can play an important role, especially during the first hours of implantation of cardiovascular stents. As a result of the discharge of positive $\mathrm{Ni}$ ions from Nitinol surfaces in biological solutions, a negatively charged interface develops. The presence of a small negative surface charge would repel the negatively charged blood components preventing stent occlusion on the initial stage of implantation. The negative charge acquired in the solutions used for surface treatments is maintained if the surface is not exposed to further treatments resulting in the further growth of the oxide layer. 
Table 1. Correlations of electrochemical parameters of Nitinol surfaces with fibrinogen adsorption and Ni release.

\begin{tabular}{|l|l|l|l|c|}
\hline Sample & $\begin{array}{l}\text { OCP } \\
(\mathrm{mV} \text { vs SCE })\end{array}$ & $\begin{array}{l}\mathrm{Rp} \\
\mathrm{M} \Omega \mathrm{cm}^{2}\end{array}$ & $\begin{array}{l}\text { Fibrinogen } \\
\text { adsorption } \\
\mathrm{ng} / \mathrm{cm}^{2}[11,12]\end{array}$ & $\begin{array}{l}\text { Ni release } \\
\mathrm{ng} / \mathrm{ml} / \mathrm{cm}^{2} \\
{[11,12]}\end{array}$ \\
\hline $\mathrm{Mp}$ & -410 & $0.15(0.1)$ & $169(32)^{*}$ & $6(1)^{*}$ \\
\hline $\mathrm{MpHt}$ & -70 & $5.7(1.7)$ & $208(47)^{*}$ & - \\
\hline $\mathrm{Ce}$ & -385 & $1.2(0.6)$ & $16(8)$ & $11(3)$ \\
\hline $\mathrm{Ep}$ & -440 & $1.8(0.6)$ & $183(18)$ & $6(3)$ \\
\hline $\mathrm{CeWb}$ & -263 & $9.3(0.4)$ & $205(19)$ & $0(0)$ \\
\hline $\mathrm{CeWbHt}$ & -185 & $7.5(0.5)$ & $290(55)$ & $1(1)$ \\
\hline
\end{tabular}

*These data were obtained on the ground surfaces 600 grit-finish. Sample designations are provided in section 2. The numbers in the parenthesis correspond to the standard deviations.

An additional relevant observation from the present study is that the current densities in the passivity region of the studied Nitinol surfaces were extremely low, from 0.01 to $1 \mu \mathrm{A} / \mathrm{cm}^{2}$. These currents are 10 to 100 times lower than those required for actually producing occlusions of the blood vessels, i.e., 5-20 $\mu \mathrm{A}$ [13].

Another important consideration relevant to the blood compatibility of Nitinol is concerning the adsorption of fibrinogen, plasma protein associated with activation of platelets and thrombosis. The results of our earlier studies $[11,12]$ indicated that fibrinogen adsorption increased gradually from $130-160 \mathrm{ng} / \mathrm{cm}^{2}$ to 300 $\mathrm{ng} / \mathrm{cm}^{2}$ with the Ti concentration on Nitinol surfaces. This correlated with the tendency of the OCP to become nobler. Because the OCP is primarily charge related [13], the observed linear dependence in fibrinogen adsorption was assigned to an alteration of surface charge, although the mechanism behind it was not clear. From the analysis presented here it follows that less noble OCPs ( $\mathrm{Mp}, \mathrm{Ce}, \mathrm{Ep})$ and a higher negative surface charge may be due to a discharge of a higher amount of $\mathrm{Ni}^{++}$ions into the corrosive solution. This charge seems to be in control of the adsorption of negatively charged fibrinogen molecules to Nitinol surfaces. Higher Rp values, implying lower corrosion rates and $\mathrm{Ni}^{++}$ion discharge, correspond to higher fibrinogen adsorption, as follows from Table 1.

The whole spectrum of platelet morphological shapes from round to spread-dendritic, fully spread and 3D aggregation in thrombi observed on various Nitinol surfaces [11,12], and also the significant differences in the number of adhered platelets [14] imply a significant variability in thrombogenicity, in agreement with the results on fibrinogen adsorption. The variable thrombogenicity that can be controlled through a surface preparation is an advantage of Nitinol that makes it suitable for diverse medical applications, from nonthrombogenic implant devices, such as vascular stents to those that require high thrombogenicity such as occlusion devices. It is appropriate to mention also that the cytokines and intracellular signaling from the activated platelets not only play an important role in early wound healing, but also guide the migration of osteogenic cells towards the implant surface, thus improving osseointegration [15]. A similar mechanism would be in place for the identified Nitinol surfaces with higher thrombogenic potentials.

\section{References}

[1] C. Chan, C. Tringwell and T. Duerig, Surf Interface Annal 15, 349 (1990).

[2] S. Shabalovskaya, J. Anderegg, J Vacuum Sci Technol A13, 2624 (1995).

[3] S. Shabalovskaya, J. Anderegg, J. Van Humbeeck, Acta Biomater 4, 103 (2008).

[4] Y. Yun, V. Turitto, K. Daigle, P. Kovacs, J. Davidson, S. Slacs, J Biomed Mater Res 32, 77 (1996).

[5] S. Shabalovskaya, H. Tian, J. Anderegg, D. Schryvers, W. Carroll, J. Van Humbeeck, Biomaterials 30, 468 (2009).

[6] S. Brown, "On methods used for corrosion testing of NiTi", International conf. on Shape Memory and Superelastic Technologie, Asilomar, USA, 2000), p. 271.

[7] G. Tepe, J. Schmehl, H. Wendel, S. Schaffner, S. Heller, M. Gianotti, et al. Biomaterials 27, 643 (2006).

[8] R. Vanderkerkhove, E. Temmerman, "Electrochemical research on the corrosion of NiTi", International conf. on Shape Memory and Superelastic Technologie, Antwerpen, 1999), p. 129.

[9] D. Mareci, G. Ungureanu, D. Aelenei, J. Mirza Rosca, Mater Corr 58, 848 (2007).

[10] L. Giner, M. Cortada, O. Rustullet, F. Gil, J. Fernandez-Truel, D. Rodriguez et al. Rev Implantol, Orale Implantodontie 29, 35 (1998).

[11] S. Shabalovskaya, J. Anderegg, G. Rondelli, W. Vanderlinden, S. De Feyter, Biomed Mater Eng 18, 1 (2008). 
[12] S. Shabalovskaya, J. Van Humbeeck, Biocompatibility of Nitinol for medical applications, Ch. 9 in: Shape Memory Alloys for Medical Applications, Woodhead Publishing Limited, Cambridge, 2008, p. 194.

[13] P. Sawyer, Ann New York Academy Sci 416, 561 (1983).

[14] D. Armitage, T. Parker, D. Grant, J Biomed Mater Res 66A, 129 (2003).

[15] J. Park, H. Gemmel, J. Davies, Biomaterials 22, 2671 (2001). 